\title{
High gravity batch and continuous processes for beer production: Evaluation of fermentation performance and beer quality $\ddagger$
}

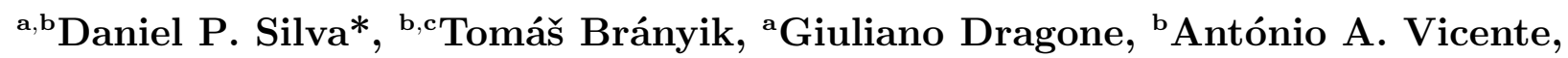

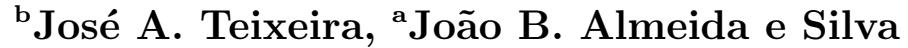

\author{
${ }^{a}$ Department of Biotechnology, Engineering School of Lorena, University of São Paulo, \\ P.O.Box116, 12602-810, Lorena-SP, Brazil \\ ${ }^{\mathrm{b}}$ Institute for Biotechnology and Bioengineering, Centre of Biological Engineering, University of Minho, \\ 4710-057, Braga, Portugal \\ ${ }^{\mathrm{c}}$ Department of Fermentation Chemistry and Bioengineering, Institute of Chemical Technology, \\ Technická 5, 16628 Prague, Czech Republic
}

Received 31 March 2007; Revised 31 July 2007; Accepted 3 August 2007

\begin{abstract}
This study deals with two innovative brewing processes, high gravity batch and complete continuous beer fermentation systems. The results show a significant influence of the variables such as concentration and temperature on the yield factor of the substrate into ethanol and consequently on the productivity of the high gravity batch process. The technological feasibility of continuous production of beer based on yeast immobilization on cheap alternative carriers was also demonstrated. The influence of process parameters on fermentation performance and quality of the obtained beers was studied by sensorial analysis. No significant difference in the degree of acceptance between the obtained products and some traditional market brands was found.

(c) 2008 Institute of Chemistry, Slovak Academy of Sciences
\end{abstract}

Keywords: beer, fermentation, high gravity, continuous, immobilization, sensorial analysis

\section{Introduction}

Beer was produced without any knowledge on microbiology or enzymology thousands of years ago. It is true that brewing has a long tradition, but it is also true that brewing has been, and still is, in the forefront of biotechnological development (Linko et al., 1998). Research in brewing, over the past three decades, has been focused on the application of different fermentation processes mainly to facilitate the beer production and consequently to reduce the production costs (Linko et al., 1998; Bamforth, 2000). This need to produce beer of good quality in a short time and in the least expensive way has prompted many breweries to use new and modern processes.
High gravity brewing (HGB) involves preparation and fermentation of media with a wort concentration higher than $12^{\circ} \mathrm{P}$ (degrees Plato), which is the weight of the extract or the sugar equivalent in $100 \mathrm{~g}$ of the solution at $20^{\circ} \mathrm{C}$. Traditional brewing uses worts of 10 $12^{\circ} \mathrm{P}$ to produce beers with $4-5$ vol. $\%$ ethanol content. By increasing the wort concentration, higher levels of ethanol per given plant capacity can be achieved and substantial savings can be attained by the brewer; the plant efficiency and capacity are increased; labour, energy, and capital costs are reduced (McCaig et al., 1992; Russell \& Stewart, 1995; Casey et al., 1984). After preparation, the beer is adjusted to the desired ethanol concentration with oxygen-free water, which makes the HGB of considerable interest (Linko et al.,

\footnotetext{
*Corresponding author, e-mail: silvadp@deb.uminho.pt, silvadp@hotmail.com

$\ddagger$ Presented at the 34th International Conference of the Slovak Society of Chemical Engineering, Tatranské Matliare, 21-25 May 2007.
} 


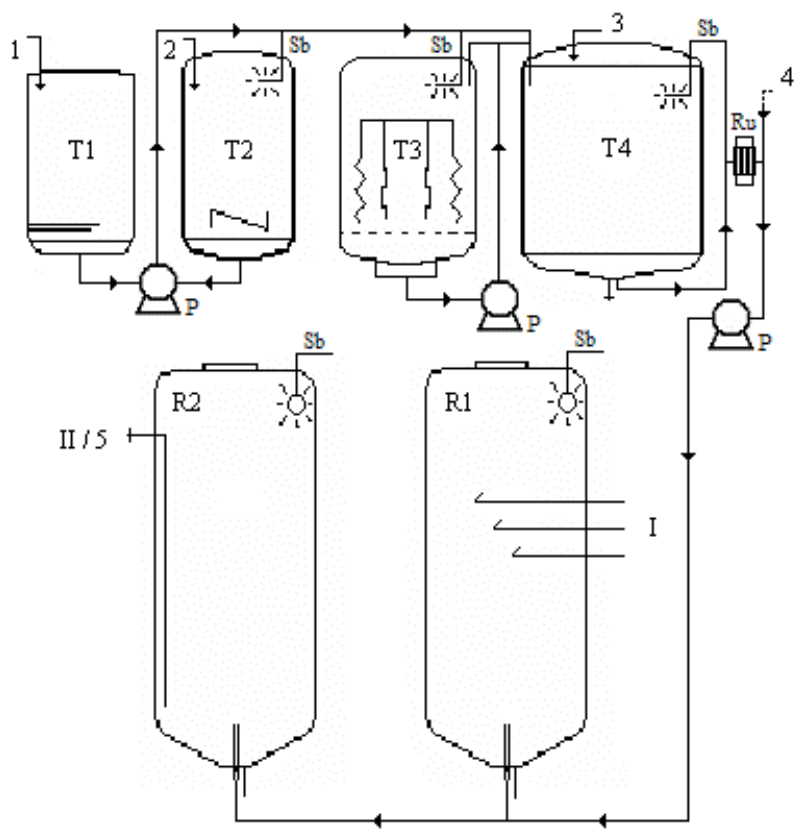

Fig. 1. Reactor system for batch beer fermentation (Microbrewery Pilot Plant EEL/Brazil): T1 hot water tank, T2 wort preparation tank, T3 filtration tank, T4 boiling tank, P pumps, Sb spray-balls (in-line cleaning system), Ru refrigeration unit, R1 fermentation/maturation reactor, R2 dilution tank, I-II sampling points, 1 water supply, 2 malt supply, 3 adjuncts (high maltose) and hops supply, 4 air supply, 5 maturated beer (final product).

1998). On the other hand, production of beer by the continuous process using immobilized cells has also been considered as a very promising technology. The use of immobilized cells in the fermentation process and their potential advantages over the free cell systems have been widely studied and reviewed (Plessas et al., 2007; Juraščík et al., 2006; Kourkoutas et al., 2004; Kourkoutas et al., 2001).

The quality of the final product must, however, be ensured when new techniques are applied to brewing processes (Linko et al., 1998). An increased productivity using different and modern brewing processes cannot be achieved at the expense of an unbalanced flavour profile of the final product and, therefore is the process optimization indispensable for any technological innovation. The goal of this work was to study the applicability of processes such as HGB and continuous fermentation for beer production in terms of fermentation parameters and sensorial quality of the final product. The influences of wort concentration and fermentation temperature on high gravity fermentation were evaluated using statistical analysis as a tool in the optimization process of these variables. The use of two alternative cellulose-based carrier materials for brewing yeast immobilization was examined in the complete continuous beer process (fermentation and maturation).

\section{Experimental}

\section{Batch beer fermentation by $H G B$}

The yeast strain used in the high gravity batch process was a commercial lager brewing strain (Saccharomyces cerevisiae). The yeast biomass for initial inoculation in the fermentation reactor was cultivated first on a rotary shaker, then in a $40 \mathrm{dm}^{3}$ stainless steel vessel under aerobic conditions until the cell concentration of $10-20 \times 10^{6} \mathrm{~cm}^{-3}$ was achieved.

Static fermentations were performed in a $180 \mathrm{dm}^{3}$ cylindrical-conical reactor with $140 \mathrm{dm}^{3}$ working volume at different temperatures $\left(9-16^{\circ} \mathrm{C}\right)$ and wort concentrations $\left(14-21^{\circ} \mathrm{P}\right)$. The wort used in this process was produced according to conventional brewing techniques in the pilot plant used for the experiments (Microbrewery Pilot Plant of the Department of Biotechnology, Engineering School of Lorena, University of São Paulo USP/Brazil, Fig. 1). High maltose syrup MOR-REX 1557 (Corn Products Brazil) was used to change the concentration of the wort from $12^{\circ} \mathrm{P}$ to $14-$ $21^{\circ} \mathrm{P}$. The initial $\mathrm{pH}$ was changed to 4.5 and the initial dissolved oxygen concentration was $20 \mathrm{mg} \mathrm{dm}^{-3}$.

The experiment was performed using the $2^{2}$ full factorial star design with the wort concentration and fermentation temperature factors on five coded levels leading to ten experiments. The ethanol yield factor after $78 \mathrm{~h} Y_{\mathrm{P} / \mathrm{S}}$ was considered the dependent variable - response.

During fermentation, samples were taken in duplicate at specified intervals and the yeast was removed by centrifugation at $4000 \mathrm{~g}$ for $20 \mathrm{~min}$. The apparent extract and ethanol concentrations in the supernatants were measured at $20^{\circ} \mathrm{C}$ using an automatic beer analyser (Beer Analyser 2, Anton Paar, Graz, Austria). The yeast cell number was determined using a Neubauer counting chamber and the viability 
was determined by methylene blue staining. All analyses were based on the techniques described in ASBC (1996).

Sensorial analysis was carried out by 40 untrained consumers of Brazilian nationality who assessed the overall acceptability of the beers in comparative analyses. Samples of the experimental beer and the Brazilian commercial beer brands were poured into black glasses $\left(90 \mathrm{~cm}^{3}\right)$ and were tasted at temperatures between $6^{\circ} \mathrm{C}$ and $8^{\circ} \mathrm{C}$. Statistical analysis of the results was done by the Analysis of Variance (ANOVA) and the Tukey tests $(P \leq 0.05)$. All sensorial tests (STest) were also based on the techniques described in ASBC (1996).

\section{Complete continuous beer fermentation by im- mobilized yeast}

The yeast strain used in the continuous system was another commercial lager brewing strain (Saccharomyces cerevisiae strain) supplied by Unicer-Bebidas de Portugal (UNICER, S.A.). The inoculum was cultivated in $0.5 \mathrm{dm}^{3}$ of complex medium under aerobic conditions on a rotary shaker. The composition of the complex medium was $\left(\mathrm{g} \mathrm{dm}^{-3}\right): \mathrm{KH}_{2} \mathrm{PO}_{4}, 5.0$; $\left(\mathrm{NH}_{4}\right)_{2} \mathrm{SO}_{4}, 2.0 ; \mathrm{MgSO}_{4} \cdot 7 \mathrm{H}_{2} \mathrm{O}, 0.4 ;$ yeast extract, 1.0 ; glucose, 10.0. A medium of the same composition was used during the initial biomass attachment phase. The wort used in this process $\left(12^{\circ} \mathrm{P}\right)$ was supplied by UNICER, S.A. The experiments of the complete continuous beer fermentation were carried out in the Pilot Laboratory of the Department of Biological Engineering, University of Minho UMINHO/Portugal (Fig. 2).

The immobilized cell reactor system used in this work consisted of a concentric draught tube type gaslift reactor for primary beer fermentation with the total working volume of $2.9 \mathrm{dm}^{3}$ (R1), a sedimentation tank for biomass removal with $0.7 \mathrm{dm}^{3}$ volume (R2), and a packed-bed reactor for beer maturation with $1.6 \mathrm{dm}^{3}$ total working volume (R3). The immobilization matrixes applied were: spent grain particles (R1), no carrier (R2), corncob cylinders (R3). Prior to use, dry spent grains were cleaned by acidic hydrolysis $(3 \mathrm{vol} \% \mathrm{HCl})$ followed by a delignification in $20 \mathrm{~g} \mathrm{dm}^{-3} \mathrm{NaOH}$, the carrier was then washed several times with water and dried (Brányik et al., 2001). Cylindrical corncobs were cut into slices (diameter ca. 2-3 cm, height ca. $1 \mathrm{~cm}$ ), cut in two pieces along the width, and sterilized three times in distilled water. Between the sterilizations, they were washed in running water $\left(20 \mathrm{dm}^{3}\right)$ in order to remove all flavour active compounds. The dimensions of the concentric draught tube type reactor (R1) with an enlarged top section for degassing are: down comer height $44 \mathrm{~cm}$, diameter $7 \mathrm{~cm}$; draught tube height $41 \mathrm{~cm}$, diameter 3.2 $\mathrm{cm}$; cylindrical part height $8 \mathrm{~cm}$, diameter $14 \mathrm{~cm}$. The angle between the conical sector and the main body

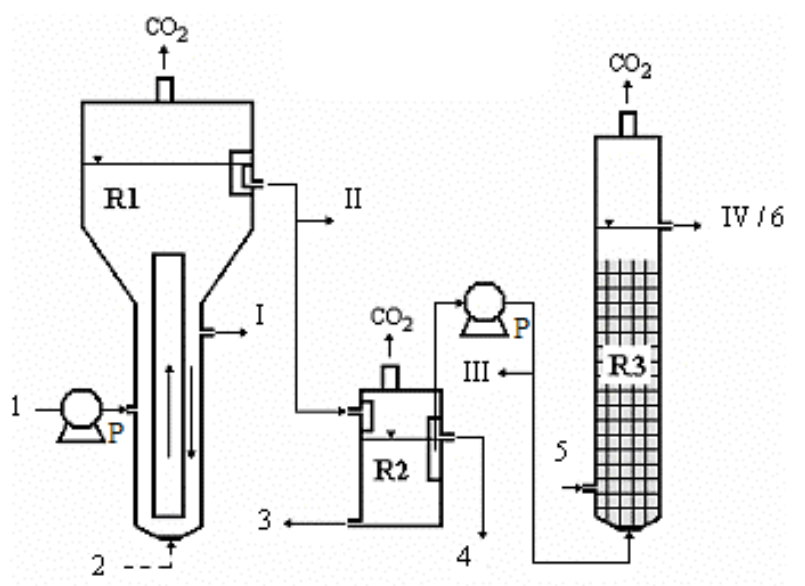

Fig. 2. Immobilized yeast reactor system for continuous beer fermentation (laboratory scale): R1 main fermentation reactor, $\mathrm{R} 2$ sedimentation tank, $\mathrm{R} 3$ maturation reactor, $\mathrm{P}$ peristaltic pumps, 1 wort supply, 2 gas supply, 3 excess biomass outlet, 4 excess young beer outlet, 5 washing solution (physiological), 6 matured beer (final product), I-IV sampling points.

was $51^{\circ}$. Gas injection was realized through a perforated plate with 5 holes (diameter $0.5 \mathrm{~mm}$ ), placed $2.5 \mathrm{~cm}$ below the annulus of the riser. The outflow of the reactor was placed behind a sedimentation barrier to minimise carrier losses. Both reactors, R2 and R3, were cylindrical with the inside diameter of $8.5 \mathrm{~cm}$ and $7 \mathrm{~cm}$ and the total working height of $12.5 \mathrm{~cm}$ and 42 $\mathrm{cm}$, respectively. R3 was operated in the upward flow. Internal temperatures in $\mathrm{R} 1\left(16^{\circ} \mathrm{C}\right), \mathrm{R} 2\left(9^{\circ} \mathrm{C}\right)$, and $\mathrm{R} 3$ $\left(2^{\circ} \mathrm{C}\right)$ were maintained by means of a cooling coil connected to a refrigeration bath. The air flow rate into R1 was adjusted using a mass flow controller (Hastings 202D, Teledyne Hastings Instruments, Hampton, Virginia, USA), while the $\mathrm{CO}_{2}$ flow rate was regulated by a rotameter.

At the start, R1 was filled with $40 \mathrm{~g}$ of dry spent grains sterilized in $1.5 \mathrm{dm}^{3}$ of distilled water and fed with $0.4 \mathrm{dm}^{3} \mathrm{~min}^{-1}$ of sterile gas. Similarly, R3 was filled with $140 \mathrm{~g}$ of dry corncob particles. R1 was subsequently charged with the complex medium and then inoculated with $1 \mathrm{dm}^{3}$ of the yeast cell suspension. After $24 \mathrm{~h}$ of the batch growth, the start-up period of R1 was initiated. The complex medium was fed into the continuous system at the total residence time, $\mathrm{RT}_{\text {tot }}$, of $17 \mathrm{~h}$, the value of which decreased to $9 \mathrm{~h}$ after 168 $\mathrm{h}$ of the operation. After $225 \mathrm{~h}$ of the start-up period, the complex medium was changed to sterilized wort $\left(50 \mathrm{dm}^{3}\right.$, sterilized for $40 \mathrm{~min}$ at $\left.120^{\circ} \mathrm{C}\right)$ which was used throughout the whole fermentation experiment at $\mathrm{RT}_{\text {tot }}=22-52 \mathrm{~h}$. The wort was kept in a refrigeration unit $\left(6-8^{\circ} \mathrm{C}\right)$ under $\mathrm{N}_{2}$ atmosphere during the whole experiment. During wort fermentation, the total gas flow rate (mixture of air and $\mathrm{CO}_{2}$ ) into $\mathrm{R} 1$ was kept at $0.4 \mathrm{dm}^{3} \mathrm{~min}^{-1}$ with different proportions of air in the mixture. The continuous system was 
Table 1. Experimental design and results according to the $2^{2}$ full factorial star design

\begin{tabular}{|c|c|c|c|c|c|}
\hline \multirow{2}{*}{ Runs } & \multicolumn{2}{|c|}{ Independent Variable } & \multicolumn{2}{|c|}{ Coded Variable } & \multirow{2}{*}{$\frac{\text { Response }}{Y_{\mathrm{P} / \mathrm{S}} /\left(\mathrm{g} \mathrm{g}^{-1}\right)}$} \\
\hline & $c($ wort $) /{ }^{\circ} \mathrm{P}$ & $\theta /{ }^{\circ} \mathrm{C}$ & $X_{1}$ & $X_{2}$ & \\
\hline 1 & 15 & 10 & -1 & -1 & 0.29 \\
\hline 2 & 20 & 10 & +1 & -1 & 0.00 \\
\hline 3 & 15 & 15 & -1 & +1 & 0.39 \\
\hline 4 & 20 & 15 & +1 & +1 & 0.30 \\
\hline 5 & 14 & 12.5 & $-2^{1 / 2}$ & 0 & 0.44 \\
\hline 6 & 17.5 & 9 & 0 & $-2^{1 / 2}$ & 0.03 \\
\hline 7 & 21 & 12.5 & $+2^{1 / 2}$ & 0 & 0.20 \\
\hline 8 & 17.5 & 16 & 0 & $+2^{1 / 2}$ & 0.42 \\
\hline 9 & 17.5 & 12.5 & 0 & 0 & 0.33 \\
\hline 10 & 17.5 & 12.5 & 0 & 0 & 0.34 \\
\hline
\end{tabular}

considered to be in steady state after the period of 5 $\mathrm{RT}_{\text {tot }}$.

Analysis of wort, young beer (partially fermented wort leaving R1) and beer for specific gravity, original extract, and alcohol was performed by SCABA 5600 (Automatic Beer Analyser, Foss Analytical, Slangerupgade, Denmark).

For immobilized biomass determination, samples of biocatalyst (carrier + immobilized cells) were twice washed with $0.1 \mathrm{dm}^{3}$ of distilled water in order to remove the free cells captured between the carrier particles. The bulk liquid was removed with a syringe, and the biocatalyst was then washed with $0.4 \mathrm{dm}^{3}$ of distilled water on a paper filter in order to remove the components of the medium from the sample. The biocatalyst together with the biomass liberated from the carrier during the washing were removed from the filter, homogenized, and dried at $105^{\circ} \mathrm{C}$ for $12 \mathrm{~h}$. An amount of approximately $0.2 \mathrm{~g}$ of dry biocatalyst with $50 \mathrm{dm}^{3}$ of $30 \mathrm{~g} \mathrm{dm}^{-3} \mathrm{NaOH}$ solution was shaken in an Erlenmeyer flask at $120 \mathrm{~min}^{-1}$ for $24 \mathrm{~h}$. In this process, the immobilized cells were completely removed from the carrier, as was verified under the microscope. The cell-free carrier was again washed on the filter $(0.4$ $\mathrm{dm}^{3}$ of distilled water) and dried at $105^{\circ} \mathrm{C}$ for $5 \mathrm{~h}$. The amount of immobilized yeast biomass was determined from the mass difference before and after the treatment with caustic. Corrections of biomass mass for the losses of carrier were carried out by blank experiments with a clean carrier. The detailed procedure of the immobilized biomass determination can be found in Brányik et al., (2004). Cell viability was measured by counting dead cells stained with methylene blue according to the current EBC recommended methods (Analytica-EBC, 2000).

The consumer acceptance tests of the experimental beer and the Portuguese commercial beer brands were carried out by at least 30 untrained consumers of the Portuguese nationality. The samples of beer prepared in the continuous process were collected under $\mathrm{N}_{2}$ atmosphere $24 \mathrm{~h}$ before tasting and stored in PET bottles at $4^{\circ} \mathrm{C}$. The acceptance tests, their statististi- cal analysis and the sensorial tests were performed in the same way as described above for HGB process.

\section{Results and discussion}

Although HGB is a process with many advantages, the fermentation of concentrated worts can have a negative effect on the yeast performance due to the elevated osmotic pressure and the production of high levels of ethanol (Almeida et al., 2001; Pratt-Marshall et al., 2002; Pratt-Marshall et al., 2003). D'Amore (1992) reported that when the initial wort gravity was increased, the rate and extent of the fermentation decreased and the amount of ethanol produced was lower than the one theoretically expected. Therefore, the process conditions, such as concentration, temperature, oxygen level, and cell pitching, have to be optimized for the HGB process. Factorial designs have been largely employed in the optimization of the fermentative process due to the possibility of studying several variables within a reduced number of experiments. This methodology also allows verifying the individual factor effects and their interactions for the response.

In this work, the effects of two variables, wort gravity and fermentation temperature on the ethanol production during the HGB process were simultaneously investigated employing a full factorial design, and the data were analyzed using the Design-expert (version 5.0, Stat-Ease Inc., USA) and the Statgraphics programs (version 4.1). Thus, experiments were planned to obtain a quadratic model of $2 \times 2$ trials plus a star configuration $\left(\alpha= \pm 2^{1 / 2}\right)$ and two replicates at the central point.

Table 1 shows the design together with the response factor used in this study. After fitting the experimental data (Table 2), the fact that both variables show a significant effect at the $99 \%$ confidence level was verified. A significant negative effect was observed of the wort concentration factor whereas a significant positive effect was obtained for the fermentation temperature. 
Table 2. Estimated effects, standard errors and Student's $t$-test for substrate-to-ethanol conversion factor $\left(Y_{\mathrm{P} / \mathrm{S}}\right)$ using the $2^{2}$ full factorial star design

\begin{tabular}{lccc}
\hline Variable & Estimated effect & Standard error & \multicolumn{1}{c}{$t$} \\
\hline Mean & 0.340 & 0.024 & - \\
$X_{1}$ : initial concentration & -0.180 & 0.024 & $7.50^{a}$ \\
$X_{2}$ : temperature & 0.238 & 0.024 & $9.92^{a}$ \\
$X_{1} \cdot X_{1}$ & -0.034 & 0.032 & 1.06 \\
$X_{2} \cdot X_{2}$ & -0.129 & 0.032 & $4.03^{b}$ \\
$X_{1} \cdot X_{2}$ & 0.100 & 0.035 & $2.86^{c}$ \\
\hline
\end{tabular}

a) $99 \%$, b) $95 \%$, and c) $90 \%$ significant level of the variables, and their interactions.

Table 3. Variance analysis of the adjusted model with the significant factors for $Y_{\mathrm{P} / \mathrm{S}}$

\begin{tabular}{lccccc}
\hline Source & $\mathrm{SS}^{a}$ & $\mathrm{DF}^{b}$ & $\mathrm{MS}^{c}$ & $F_{\text {calc }}$ & $p$ \\
\hline Model & 0.2100 & 4 & 0.052 & 42.31 & $0.0005^{d}$ \\
Residual & 0.0061 & 1 & 0.0012 & - & - \\
Lack of fit & 0.0059 & 1 & 0.0015 & 7.36 & 0.2688 \\
Pure error & 0.0002 & 1 & 0.0002 & - & - \\
\hline
\end{tabular}

a) Sum of squares. b) Degrees of freedom. c) Mean square $\left.R^{2}=0.97 . d\right) 99 \%$ significant level.

Table 4. Analysis of variance (ANOVA) of the model coefficients for $Y_{\mathrm{P} / \mathrm{S}}$

\begin{tabular}{ccccrl}
\hline Source & $\mathrm{SS}^{a}$ & $\mathrm{DF}^{b}$ & $\mathrm{MS}^{c}$ & $F$ & $p$ \\
\hline$X_{1}$ & 0.0362 & 1 & 0.0362 & 23.23 & $0.0170^{d}$ \\
$X_{2}$ & 0.1132 & 1 & 0.1132 & 72.65 & $0.0034^{e}$ \\
$X_{1}^{2}$ & 0.0013 & 1 & 0.0013 & 0.83 & 0.4282 \\
$X_{2}^{2}$ & 0.0175 & 1 & 0.0175 & 11.22 & $0.0441^{d}$ \\
$X_{1} X_{2}$ & 0.0100 & 1 & 0.0100 & 6.42 & \\
0.0852 & 0.2651 & 9 & & & \\
\hline
\end{tabular}

a) Sum of squares. b) Degrees of freedom. c) Mean square $\left.R^{2}=0.97 . d\right) 95 \%$ and e) $99 \%$ significant level.

As the wort concentration increases, the yeasts are exposed to severe conditions such as high osmotic pressure and toxicity of the produced ethanol (Stewart et al., 1988). Stewart and Russell (1993) reported that with the wort gravity above $16{ }^{\circ} \mathrm{P}$, the stress effects, due to high osmotic pressure and high ethanol levels, became more evident and resulted in a decrease in the rate and extent of fermentation. Table 3 shows an analysis of variance of the adjusted regression model which is represented by the following equation

$$
\begin{gathered}
Y_{\mathrm{P} / \mathrm{S}}=(0.32 \pm 0.024)-(0.09 \pm 0.012) X_{1}+ \\
+(0.12 \pm 0.012) X_{2}-(0.06 \pm 0.016) X_{2}^{2}+ \\
+(0.05 \pm 0.017) X_{1} X_{2}
\end{gathered}
$$

The variance analysis of the coefficients of this model is visualized in Table 4, while the graphic illustration is shown in Fig. 3. It was confirmed that the conversion values increase at higher temperatures and lower concentrations. The optimal conditions suggested by the obtained mathematical model were 14.0 ${ }^{\circ} \mathrm{P}$ and $13.5^{\circ} \mathrm{C}$.

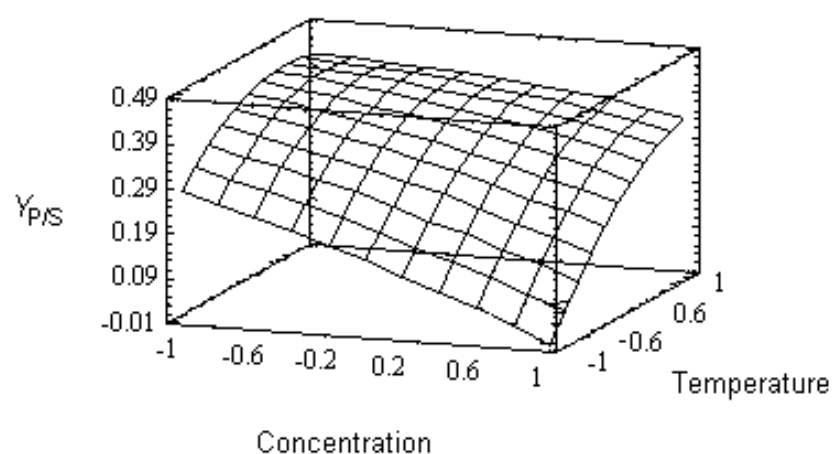

Fig. 3. Response surface described by the model Eq. (1).

Through the validation of the optimized conditions (Fig. 4), it was possible to verify the yield factor of 0.44 $\mathrm{g} \mathrm{g}^{-1}$ at $78 \mathrm{~h}$, while the proposed model indicated a value of $0.46 \mathrm{~g} \mathrm{~g}^{-1}$. Other fermentative parameters obtained were $0.50 \mathrm{~g} \mathrm{dm}^{-3} \mathrm{~h}^{-1}$ volumetric productivity at $78 \mathrm{~h}, 0.37 \mathrm{~g} \mathrm{dm}^{-3} \mathrm{~h}^{-1}$ of the total volumetric productivity, and $0.44 \mathrm{~g} \mathrm{~g}^{-1}$ yield factor at the end of the fermentative process $(130 \mathrm{~h})$. The product obtained in these conditions contained approximately by 


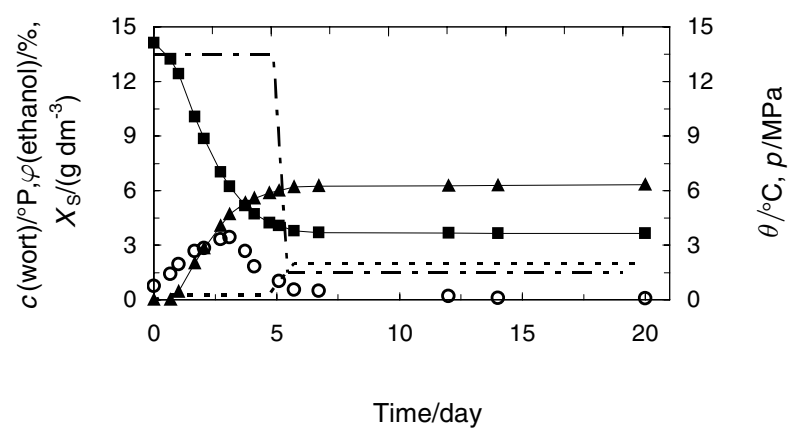

Fig. 4. Concentration of wort $(\boldsymbol{\square})$, ethanol $(\boldsymbol{\Delta})$, and cell in suspension (O), as well as temperature (dotted-dashed line) and counter pressure (dotted line) during the batch process (optimized conditions).

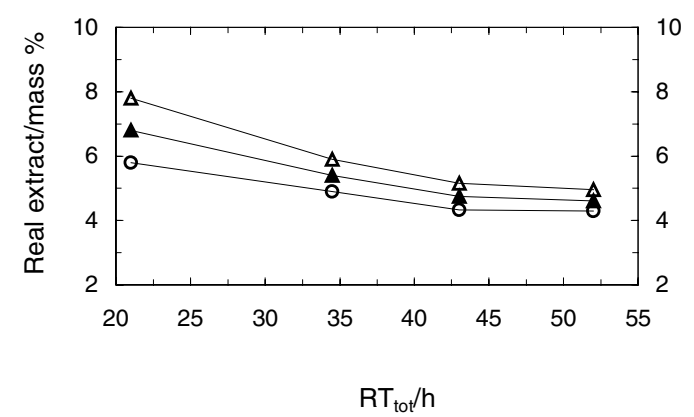

Fig. 5. Influence of total residence times $\left(R T_{\text {tot }}\right)$ on extract consumption $\left(12^{\circ} \mathrm{P}\right)$ shown as real extract remaining in R1 $(\triangle)$, R2 $(\boldsymbol{\Delta})$, and R3 (O) stage of the system, at a constant air $\left(0.02 \mathrm{dm}^{3} \mathrm{~min}^{-1}\right)$ and total gas $0.4 \mathrm{dm}^{3}$ $\min ^{-1}$ flow rate into $\mathrm{R} 1$.

$25 \%$ more ethanol than the product obtained from the maturation process in traditional conditions.

However, in such a competitive market as the brewing industry, the potential time savings offered by continuous fermentation represent a challenging dilemma to be addressed. Fermentation and maturation are stages that consume the largest amounts of time in the production of beer, which are typically between 5-7 days and 7-30 days, respectively. The continuous fermentation process based on the immobilized yeast cell technology allows producing an acceptable final product within 2-3 days (Tata et al., 1999; Dömény et al., 1998). Various supports and immobilization techniques have been proposed and tested for application in wine-making, cider-making, brewing, distillates, potable alcohol, and in the production of novel beverages (Kourkoutas et al., 2004; Kourkoutas et al, 2005; Herrero et al., 2001; Loukatos et al., 2003).

Thus, in order to compare with the high gravity process (Fig. 4), we evaluated the effects of a complete continuous system using airlift and packed-bed reactors containing brewing yeast immobilized on spent grains and corncobs as support, respectively. It was not possible to use the spent grain particles, used in the pneumatically agitated gas-lift reactor for the main fermentation (R1), in the packed-bed reactor (maturation, R3) because of their small size. A fixed bed formed by spent grain particles together with retained biomass would lead to clogging and channeling. Thus, in order to increase the void volume of the fixed bed in R3, a mechanically more resistant (non-compressible) and more granular carrier type was needed as a support for the yeast immobilization (corncobs). Fig. 5 shows the contribution of the total fermentable extract consumed in the different reactors or tanks to the fermentations in the continuous system: $(79.5 \pm 7.1) \%$ in the gas-lift reactor, $(10.8 \pm$ 4.7) $\%$ in the sedimentation tank and $(9.3 \pm 2.8) \%$ in the maturation column. At $\mathrm{RT}_{\text {tot }}$ longer than 43 $\mathrm{h}$, the beer extract content was almost independent of the residence time and was close to the limit achievable for the supplied wort. This limit was determined by the portion of fermentable sugars (ca. $70 \%$ ) in the wort extract $\left(12^{\circ} \mathrm{P}\right)$.

In the continuous fermentation, the immobilized biomass concentration on the spent grain particles in $\mathrm{R} 1$ reached its plateau after ca. 4 days of feeding with wort and then it remained rather constant (ca. 0.6 $\mathrm{g} \mathrm{g}^{-1}$, gram of immobilized cell per gram of dry carrier). The average concentration of the free cells in the outflow from R1 was ca. $3.9 \mathrm{~g} \mathrm{dm}^{-3}$ and it varied in accordance with the growth conditions $\left( \pm 1 \mathrm{~g} \mathrm{dm}^{-3}\right)$.

In an agitated gas-lift reactor, the old biocatalyst slurry can be easily replaced by clean spent grains, while in packed-bed columns with corncob particles, turbulent washing can be applied. The main reason of the inclusion of a sedimentation tank into the continuous system was to remove the free biomass from the product stream before it enters the maturation column. The effectiveness of the biomass removal was, however, only $(44 \pm 11) \%$. As a consequence, the concentration of cells at the entrance to R3 was about $2.2 \mathrm{~g} \mathrm{dm}^{-3}$. Since the average cell content in the outflow from R3 was only $1.3 \mathrm{~g} \mathrm{dm}^{-3}$, it was necessary to remove the excess of gradually accumulating biomass in this column. Such removal was achieved by a periodical (every 10 days) upward flushing of R3 with 4 $\mathrm{dm}^{3}$ of sterile physiological solution.

When new techniques are applied to the brewing process, the quality of beer must be ensured. In order to evaluate the feasibility of these two processes, the effect of operational conditions on the formation of organoleptically active compounds and sensorial character of the final product was studied.

After maturation, the product obtained in the pilot scale by the high gravity batch process was transferred to the storage tank (original pressure maintained) where the alcohol concentration (6.2 vol. \%) was adjusted to $5 \%$ in volume by dilution with carbonated and refrigerated water. This value is comparable to those found in Brazilian beer brands. In order to find out the acceptance degree of the experimen- 
Table 5. Average classification (consumer acceptance) of commercial lagers and beers from the batch process (USP/Br) and from the continuous process (UMINHO/Pt)

\begin{tabular}{lccc}
\hline Product (beer) & STest 1 & STest 2 & STest 3 \\
\hline Brazilian lager 1 & $6.3^{b}$ & - & - \\
Brazilian lager 2 & $6.1^{b}$ & - & - \\
Brazilian lager 3 & $5.8^{b}$ & $6.7^{b}$ & - \\
Brazilian lager 4 & - & $6.4^{b}$ & - \\
Batch Process 1 & - & $6.4^{b}$ & - \\
Batch Process 2 & - & - & $6.4^{b}$ \\
American lager & - & - & $6.0^{b}$ \\
Czech lager & - & - & $5.9^{b}$ \\
Continuous & & - &
\end{tabular}

a) Continuous production, no aeration of $\mathrm{R} 1, \mathrm{RT}_{\text {tot }}=29 \mathrm{~h}$. b) Statistically equal.

tal beer obtained by the high gravity batch process in optimized conditions (USP/Brazil), sensorial tests (STest) were carried out comparing this product with Brazilian lager beer brands. These tests (STest 1 and 2) did not reveal any statistically significant difference between the medium values obtained, indicating the same acceptance degree of all products (Table 5).

In the same way, also sensorial tests comparing the continuously fermented beer (UMINHO/Portugal) with commercial lager beer brands were carried out. The results of the unfiltered and non-pasteurized beer from the continuous system comparison with bottled commercial lager beers are shown in Table 5. Neither this test (STest 3) did reveal any statistically significant difference between the medium values obtained, indicating the same acceptance degree of all products (Table 5).

The control beers used in the sensorial analysis during the acceptance tests to the continuously fermented beer were foreign beer brands. When local beer brands were used, the results revealed a consumer preference in favour of Portuguese lager beers manifested by a statistically significant difference (data not shown). Trained tasters of the internal sensory panel of the Department of Biotechnology EEL/Brazil and of UNICER, SA/Portugal carried out descriptive tests classifying sensorial global parameters of the unfiltered and non-pasteurized beers produced by the high gravity batch process and by the continuous process, respectively (data not shown). The results revealed differences between the commercial Brazilian lager beers and the experimental batch product attributing higher intensity to the experimental product. The results for the continuously fermented beers and one unfiltered and non-pasteurized commercial Portuguese lager revealed the most significant difference in higher fruity (estery) fragrance and more intensive bitterness of the continuously fermented beers.

The above results show that the finished product from the HGB process and the complete continuous process using brewer's yeast immobilized on cheap carriers (spent grains, corncobs) were found by consumers (untrained tasters) to be quite acceptable from the flavour perspective and without any statistically significant dissimilarity from the medium values obtained for the commercial products. However, some "faults" of the fermented beer from the HGB process and of the continuously fermented beer found by trained/experienced tasters should be eliminated in a large-scale operation or in a complete industrial process. The beers from both processes were unfiltered and non-pasteurized products, and in the continuously fermented beers, additional wort sterilization was required leading to an oxidized or burnt aftertaste.

\section{Conclusions}

It was demonstrated that beer fermentation by HGB and complete continuous system using brewer's yeast immobilized on cheap carriers (spent grains, corncobs) show good results. Besides, in comparison with the traditional process, the advantages of the high gravity process in terms of the process productivity and maintenance of the product quality are evident only when the fermentation time remains moderate and the wort attenuation, beer flavour, and yeast viability are adequate.

The results in the continuous reactor system show a stable operation for almost 2 months indicating an interesting process meeting the prerequisites for a cost effective industrial application using brewer's yeast cell immobilization on a natural, abundant and easily available cellulosic material, fully compatible with beer. The presented continuous system stands out by its significantly shorter fermentation times, cheap carrier materials reducing the investment costs and beer with generally acceptable and sufficiently balanced flavour.

Acknowledgements. Concerning batch experiments, the authors thank the financial support from FAPESP, CAPES and CNPq (Brazil), and also the Malteria do Vale, Wallerstein Industrial e Commercial, Corn Products Brasil and JohnsonDiversey for supplying brewing materials. As for continuous fermentations, the authors thank the financial support from FAPESP/Brazil, FCT/Portugal, MS̆MT (MSM 6046137305, Czech Republic), as well as the support of Unicer S.A. 


\section{References}

Almeida, R. B., Almeida e Silva, J. B., Lima, U. A., Silva, D. P., \& Assis, A. N. (2001). Evaluation of fermentation parameters during high-gravity beer production. Brazilian Journal of Chemical Engineering, 18, 459-465.

Analytica-EBC (2000). European Brewery Convention. Nürnberg: Fachverlag Hans Carl.

ASBC (1996). Methods of Analysis of American Society of Brewing Chemists, 8a. Ed. American Society of Brewing Chemists: Saint Paul, Minnesota.

Bamforth, C. W. (2000). Brewing and brewing research: past, present and future. Journal of the Science of Food and Agriculture, 80, 1371-1378. DOI: 10.1002/1097-0010(200007)80: $9<1371:$ :AID-JSFA654>3.0.CO $; 2-\mathrm{K}$

Brányik, T., Vicente, A. A., Machado Cruz, J. M., \& Teixeira, J. A. (2001). Spent grains - a new support for brewing yeast immobilisation. Biotechnology Letters, 23, 1073-1078. DOI: 10.1023/A:1010558407475.

Brányik, T., Vicente, A. A., Oliveira, R., \& Teixeira, J. A. (2004). Physicochemical surface properties of brewing yeast influencing their immobilization onto spent grains in a continuous reactor. Biotechnology and Bioengineering, 88, 8493. DOI: $10.1002 /$ bit. 20217.

Casey, G. P., Magnus, C. A., \& Ingledew, W. M. (1984). Highgravity brewing: Effects of nutrition on yeast composition, fermentative ability, and alcohol production. Applied and Environmental Microbiology, 48, 639-646.

D'Amore, T. (1992). Cambridge prize lecture: Improving yeast fermentation performance. Journal of the Institute of Brewing, 98, 375-382.

Dömény, Z., Šmogrovičová, D., Gemeiner, P., Šturdík, E., Pátková, J., \& Malovíková, A. (1998). Continuous secondary fermentation using immobilised yeast. Biotechnology Letters, 20, 1041-1045. DOI: 10.1023/A:1005417913123.

Herrero, M., Laca, A., García, L. A., \& Díaz, M. (2001). Controlled malolactic fermentation in cider using Oenococcus oeni immobilized in alginate beads and comparison with free cell fermentation. Enzyme and Microbial Technology, 28, 3541. DOI: $10.1016 /$ S0141-0229(00)00265-9.

Juraščík, M., Hucík, M., Sikula, I., Annus, J., \& Markoš, J. (2006). Influence of biomass on hydrodynamics of an internal loop airlift reactor. Chemical Papers, 60, 441-445. DOI: 10.2478/s11696-006-0080-2.

Kourkoutas, Y., Kanellaki, M., Koutinas, A. A., \& Tzia, C. (2005). Effect of fermentation conditions and immobilization supports on the wine making. Journal of Food Engineering. 69, 115-123. DOI: 10.1016/j.jfoodeng.2004.08.003.

Kourkoutas, Y., Bekatorou, A., Banat, I. M., Marchant, R., \& Koutinas, A. A. (2004). Immobilization technologies and support materials suitable in alcohol beverages production: a review. Food Microbiology, 21, 377-397. DOI: $10.1016 /$ j.fm.2003.10.005.
Kourkoutas, Y., Komaitis, M., Koutinas, A. A., \& Kanellaki, M. (2001). Wine production using yeast immobilized on apple pieces at low and room temperatures. Journal of agricultural and food chemistry, 49, 1417-1425. DOI: 10.1021/jf000942n S0021-8561(00)00942-0.

Linko, M., Haikara, A., Ritala, A., \& Penttila, M. (1998). Recent advances in the malting and brewing industry. Journal of Biotechnology, 65, 85-98. DOI: 10.1016/S01681656(98)00135-7.

Loukatos, P., Kanellaki, M., Komaitis, M., Athanasiadis, I., \& Koutinas, A. A. (2003). A new technological approach proposed for distillate production using immobilized cells. Journal of Bioscience and Bioengineering, 95, 35-39. DOI: 10.1016/S1389-1723(03)80145-7.

McCaig, R., McKee, J., Pfisterer, E. A., Hysert, D. W., Munoz, E., \& Ingledew, W. M. (1992). Very high gravity brewing - laboratory and pilot plant trials. Journal of the American Society of the Brewing Chemists, 50, 18-26. DOI: 10.1094/ASBCJ-50-0018.

Plessas, S., Bekatorou, A., Koutinas, A. A., Soupioni, M., Banat, I. M., \& Marchant, R. (2007). Use of Saccharomyces cerevisiae cells immobilized on orange peel as biocatalyst for alcoholic fermentation. Bioresource Technology, 98, 860-865. DOI: 10.1016/j.biortech.2006.03.014.

Pratt-Marshall, P. L., Brey, S. E., deCosta, S. D., Bryce, J. H., \& Stewart, G. G. (2002). High gravity brewing-an inducer of yeast stress. Brewer's Guardian, 131(3), 22-26.

Pratt-Marshall, P. L., Bryce, J. H., \& Stewart, G. G. (2003). The effects of osmotic pressure and ethanol on yeast viability and morphology. Journal of the Institute of Brewing, 109, 218-228.

Russell, I., \& Stewart, G. G. (1995). Brewing. In Reed, G., \& Nagodawithana, T. W. (Eds.), Biotechnology. A MultiVolume Comprehensive Treatise, Vol. 9 (pp. 419-462). Weinheim: $\mathrm{VCH}$.

Stewart, G. G., D'Amore, T., Panchal, C. J., \& Russell, I. (1988). Factors that influence the ethanol tolerance of brewer's yeast strains during high gravity wort fermentations. MBAA Technical Quarterly, 25, 47-53.

Stewart, G. G., \& Russell, I. (1993). Fermentation - the "black box" of the brewing process. MBAA Technical Quarterly, 30, 159-168.

Tata, M., Bower, P., Bromberg, S., Duncombe, D., Fehring, J., Lau, V., Ryder, D., \& Stassi, P. (1999). Immobilized yeast bioreactor systems for continuous beer fermentation. Biotechnology Progress, 15, 105-113.

DOI: $10.1021 /$ bp980109z. 